\title{
The effect of midazolam as premedication on the quality of postoperative recovery after laparotomy: a randomized clinical trial
}

\section{Effet du midazolam en prémédication sur la qualité de la récupération postopératoire après une laparotomie : une étude clinique randomisée}

\author{
Stefan van Beek, MD, MSc (D) • Jeroen Kroon, MD, MSc • Koen Rijs, BSc • Hendrik-Jan Mijderwijk, MD, PhD • \\ Markus Klimek, MD, PhD • Robert J. Stolker, MD, PhD
}

Received: 24 December 2018/Revised: 21 July 2019/Accepted: 27 July 2019/Published online: 1 October 2019

(C) The Author(s) 2019

\begin{abstract}
Purpose Despite the uncertain effects of anxiolytic premedication with benzodiazepines on the quality of postoperative recovery, perioperative benzodiazepine administration is still a common practice in many hospitals. We evaluated the effect of premedication with midazolam on the quality of recovery in hospitalized patients undergoing a laparotomy.

Methods We conducted a single-centre randomized placebo-controlled, double-blinded clinical trial from July 2014 to September 2015. We included 192 patients aged $>18$ yr scheduled for elective laparotomy with a planned postoperative stay of $\geq$ three days. Participants were randomized into two groups to receive either midazolam $3 \mathrm{mg}$ or sodium chloride 0.9\% intravenously as premedication prior to surgery. Patients were followed up for up to one week after surgery. The primary outcome was the Quality of Recovery-40 (QoR-40) score on postoperative day (POD) 3. The secondary outcomes included the QoR-40 score on POD 7, and the StateTrait Anxiety Inventory, State-Trait Anger Scale, Multidimensional Fatigue Inventory, and the Hospital Anxiety and Depression Scale scores.

Results The mean (standard deviation) postoperative QoR-40 scores on POD 3 were not significantly different
\end{abstract}

S. van Beek, MD, MSc ( $\square) \cdot$ J. Kroon, MD, MSc .

K. Rijs, BSc · H.-J. Mijderwijk, MD, PhD .

M. Klimek, MD, PhD · R. J. Stolker, MD, PhD

Department of Anesthesiology, Erasmus University Medical

Centre, PO 2040, 3000 CA Rotterdam, The Netherlands

e-mail: s.vanbeek@erasmusmc.nl in the midazolam group compared with controls [166.4 (17.0) vs 163.9 (19.8), respectively; mean difference, 2.3; 95\% confidence interval, -2.9 to $8.4 ; P=0.35]$. There were no between-group differences in any of the secondary outcomes.

Conclusions Administration of midazolam as premedication for laparotomy patients did not improve the quality of recovery up to one week after surgery. General prescription of midazolam as premedication can be questioned and might only suit some patients.

Trial registration $w w w . c l i n i c a l t r i a l s . g o v(N C T 01993459)$; registered 29 October, 2013.

Résumé

Objectif En dépit des effets incertains d'une prémédication anxiolytique à l'aide de benzodiazépines sur la qualité de la récupération postopératoire, l'administration périopératoire de benzodiazépine demeure pratique courante dans bon nombre d'hopitaux. Nous avons évalué l'effet du midazolam en prémédication sur la qualité de la récupération des patients hospitalisés subissant une laparotomie.

Méthode Nous avons réalisé une étude clinique monocentrique randomisée, à double insu et contrôlée par placebo entre les mois de juillet 2014 et septembre 2015. Nous avons inclus 192 patients âgés de plus de 18 ans devant subir une laparotomie non urgente suivie d'un séjour postopératoire planifié d'au moins trois jours. Les participants ont été randomisés en deux groupes, le premier recevant en prémédication pré-chirurgie une solution intraveineuse de $3 \mathrm{mg}$ de midazolam et le second du chlorure de sodium 0,9\%. Les patients ont été 


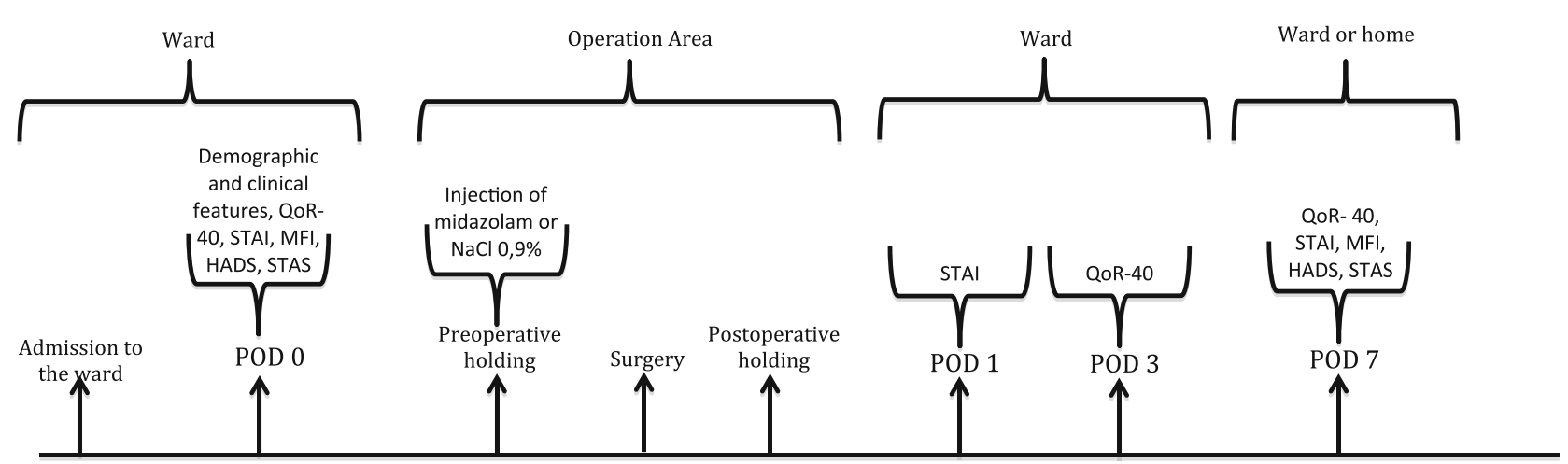

Timeline of the study. POD 0: baseline assessment preoperatively on the day of surgery (self-reported questionnaire); POD 1: first postoperative day after surgery, (selfreported questionnaire); POD 3: third postoperative day (self-reported questionnaire); POD 7: seventh postoperative day (self-reported questionnaire); HADS, Hospital Anxiety and Depression Scale; MFI, Multidimensional Fatigue Inventory; QoR-40: Quality of Recovery Score-40; STAI, State-Trait Anxiety Inventory; STAS, State-Trait Anger Scale.

Fig. 1 Timeline of the study. POD $0=$ baseline assessment preoperatively on the day of surgery (self-reported questionnaire); POD 1 = first postoperative day after surgery, (self-reported questionnaire); $\mathrm{POD} 3=$ third postoperative day (self-reported questionnaire); POD $7=$ seventh postoperative day (self-reported

suivis pour une durée maximale d'une semaine après la chirurgie. Le critère d'évaluation principal était le score QdR-40 (Qualité de la récupération - 40) au $3^{\text {ème jour }}$ postopératoire (JP3). Les critères d'évaluation secondaires comprenaient le score QdR-40 au JP7 ainsi que les scores sur les échelles suivantes: le STAI (State-Trait Anxiety Inventory - Questionnaire sur l'anxiété chronique et réactionnelle), la STAS (State-Trait Anger Scale Échelle de colère-état et colère-trait), le MFI (Multidimensional Fatigue Inventory - Inventaire multidimensionnel de la fatigue) et le HADS (Hospital Anxiety and Depression Scale - Échelle d'anxiété et de dépression en milieu hospitalier).

Résultats Les scores postopératoires moyens (écart type) sur l'échelle $Q d R-40$ au JP3 n'ont pas démontré de différence significative entre le groupe midazolam et le groupe témoin $[166,4 \quad(17,0)$ vs $163,9 \quad(19,8)$, respectivement; différence moyenne, 2,3; intervalle de confiance $95 \%,-2,9$ à 8,4; $P=0,35]$. Aucune différence intergroupe n'a été observée dans les critères d'évaluation secondaires.

Conclusion L'administration de midazolam en prémédication chez les patients devant subir une laparotomie n'a pas amélioré la qualité de la récupération dans la première semaine après la chirurgie. Une administration systématique de midazolam en prémédication peut être remise en question et pourrait ne convenir qu'à certains patients.

Enregistrement de l'étude www.clinicaltrials.gov (NCT01993459); enregistrée le 29 octobre 2013. questionnaire); HADS = Hospital Anxiety and Depression Scale; MFI $=$ Multidimensional Fatigue Inventory; QoR-40 = Quality of Recovery Score-40; STAI = State-Trait Anxiety Inventory; STAS = State-Trait Anger Scale.

Despite the widespread use of benzodiazepines as premedication based on their anxiolytic, amnestic, and sedative effects, there is still debate whether they improve the quality of postoperative recovery. Many patients develop negative emotions when they are scheduled for a surgical procedure. These may include anxiety, depression, aggression, fatigue, and physical complaints. Anxiety is the most well-known and prominent preoperative complaint. ${ }^{1-4}$ Preoperative anxiety can have adverse effects on the perioperative course because it correlates with high postoperative anxiety, increased postoperative pain, increased need for analgesics, postoperative nausea and vomiting (PONV), and prolonged hospital stay. ${ }^{5-7}$ Furthermore, it has been shown that preoperative anxiety has a negative effect on the induction of anesthesia and recovery. ${ }^{8,9}$

Anxiolytic premedication by benzodiazepines could thus be a useful treatment for patients who suffer from preoperative anxiety. ${ }^{10,11}$ Moreover, premedication with midazolam lowers the incidence of PONV, which might contribute to a better postoperative experience for patients. ${ }^{12,13}$ Nevertheless, whether midazolam improves the overall quality of postoperative recovery is unknown. ${ }^{14}$ For example, in two trials, one in ambulatory surgery patients and the other in patients undergoing scheduled inpatient surgery, lorazepam had no beneficial effect on the quality of postoperative recovery and actually resulted in a slower reduction in anxiety and increased aggression after surgery. ${ }^{15,16}$ These results do not necessarily indicate that all sedative premedication is unwarranted but do suggest that the use of lorazepam might not always be appropriate. As midazolam has anxiolytic properties of relatively shorter duration, it could be a more appropriate 


\section{Enrollment}

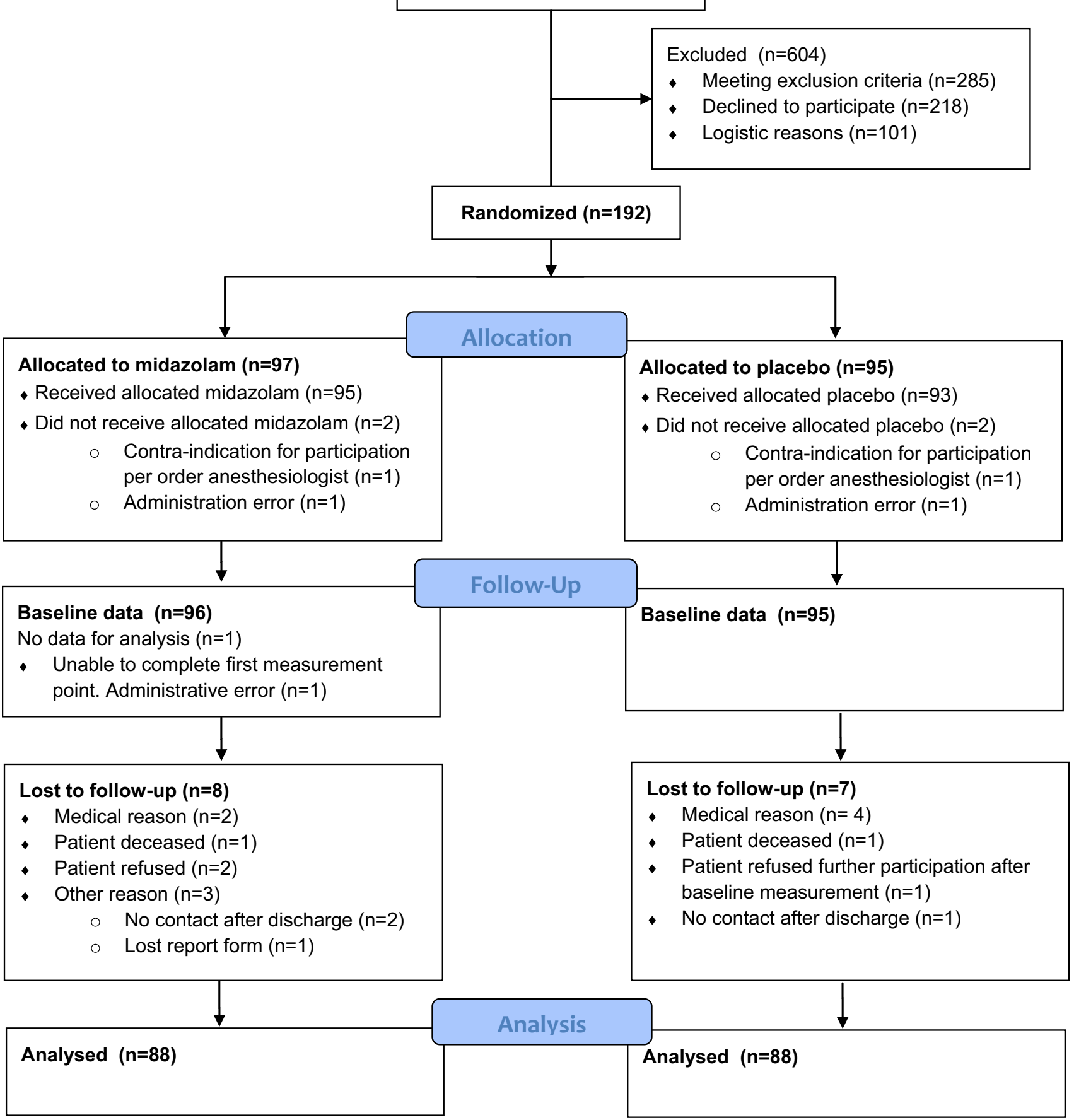

Fig. 2 Flowchart showing patient flow up to one week following intention-to-treat.

benzodiazepine to improve the quality of postoperative recovery.

Accordingly, the primary objective of this study was to determine the effect of midazolam premedication on the quality of recovery of patients up to one week after surgery. We hypothesized that premedication with midazolam for patients undergoing major surgery (laparotomy) improves the quality of postoperative recovery. The secondary objective was to assess the effects of midazolam on anxiety, aggression, fatigue, and depression in the postoperative period. 


\section{Methods}

The Medical Ethical Committee of Erasmus University Medical Centre (Rotterdam, The Netherlands) together with the Netherlands Central Committee on Research involving Human Subjects approved the study protocol on 18 June 2013. The trial was registered prior to participant enrolment at clinicaltrials.gov (NCT01993459; date of registration: 29 October, 2013). All participants provided written informed consent prior to enrolment in the study.

\section{Study population}

Between 11 July 2014 and 28 September 2015, 192 consecutive patients were recruited from the hospital's departments of general surgery, gynecology, and urology. Inclusion criteria were the requirement for laparotomy, planned postoperative hospital stay for $\geq$ three days, and age $\geq 18$ yr. There was no upper age limit for inclusion. Exclusion criteria for participants were any contraindication to midazolam administration, intellectual disability, insufficient command of the Dutch language, or current use of psychopharmaceutical drugs (e.g., antidepressants, antipsychotics, anticonvulsants, and benzodiazepines).

\section{Study design}

Participants were randomized in a parallel group design with varying block sizes (8-10-12). The allocation ratio was $1: 1$, to either midazolam or equal volume of sodium chloride $(\mathrm{NaCl}) \quad 0.9 \%$ (placebo). An independent statistician performed the randomization with a computer-generated table. Upon inclusion, patients were assigned successive numbers. Independent nurses with access to the randomization table prepared the study medication. The researchers, patients, and all other healthcare professionals were blinded to the treatment allocation.

\section{Intervention}

Figure 1 shows a timeline of all study procedures. All elective surgery patients received written information about the study at least one week before surgery. After admission on the ward, a member of the research group obtained written informed consent from eligible patients. While waiting for surgery, patients completed the first set of questionnaires (preoperative, postoperative day [POD] $0)$. In the preoperative holding area, the independent recovery nurses prepared the medication according to the group assignment document. Blinding for patients was achieved by preparation of the various transparent fluids in identical syringes. Midazolam was diluted in $\mathrm{NaCl} 0.9 \%$ to $1 \mathrm{mg} \cdot \mathrm{mL}^{-1}$. Another nurse blinded to the treatment condition injected the single dose of $3 \mathrm{~mL}$ midazolam solution or $3 \mathrm{~mL} \mathrm{NaCl} 0.9 \%$ iv $45-60 \mathrm{~min}$ before induction of anesthesia. No additional premedication or other benzodiazepine administration was allowed. Postoperative care was carried out according to our institution's (Enhanced Recovery after Surgery [ERAS]) protocol. Patients completed questionnaires after surgery on postoperative day (POD) 1, POD 3, and POD 7. The healthcare professionals who administered the questionnaires were blinded to the treatment allocation.

Assessment of outcomes

\section{Primary outcome}

The primary outcome, quality of recovery after surgery, was measured with the 40-item Quality of Recovery Score40 (QoR-40) on POD 3. ${ }^{17,18}$ The Qor-40 contains five scales assessing physical comfort, emotional state, physical independence, psychological support, and pain. All items are scored on a five-point Likert scale, and the QoR-40 score is calculated as the total sum of the scores: the higher the score, the higher the quality of recovery (minimum score 40, maximum score 200). The QoR-40 has a good internal consistency (Cronbach's $\alpha=0.93$ ). ${ }^{18}$

\section{Secondary outcomes}

Secondary outcomes included the QoR-40 on POD 7, anxiety, fatigue, depressive mood, and aggression. All questionnaires were validated Dutch versions with high internal consistencies. ${ }^{19-23}$ Anxiety was measured at POD 1 and 7 with the State-Trait Anxiety questionnaire (STAI) measuring both trait anxiety (general feeling of anxiety) and state anxiety (current feeling of anxiety). ${ }^{19}$ Both questionnaires have two 20-item scales. A higher score signifies a higher level of anxiety (score range 20-80). Fatigue was measured with the Multidimensional Fatigue Inventory (MFI) measuring general fatigue, physical fatigue, mental fatigue, reduced motivation, and reduced activity. ${ }^{20}$ Each section has four items. A higher total score indicates increased fatigue (score range 20-100). The Hospital Anxiety and Depression Scale (HADS) was used to measure depressive moods and consists of two 7-item scales, one measuring depression and one measuring anxiety. ${ }^{21,22}$ A higher total score indicates higher degrees of depressive moods (score range 0-21). Aggression was measured with the State-Trait Anger Scale (STAS), measuring both state aggression (at this moment) and trait aggression (general feeling). ${ }^{23}$ Both parts have ten- 
item scales. A high STAS indicates high levels of aggression (score range 10-40).

Demographic measures were assessed at baseline and during the timeline of the study. During surgery, we recorded a number of perioperative parameters (e.g., heart rate, blood pressure, temperature, saturation, duration of surgery, complications).

\section{Statistical analysis}

Sample size calculations were based on the primary outcome variable, i.e., QoR-40 at POD 3. According to Myles et al. and our previous study, the preoperative mean (standard deviation [SD]) of QoR-40 is 183 (17). ${ }^{15,18} \mathrm{We}$ expected that the clinical effect would equal half of the standard deviation (i.e., $0.5 \times 17=8.5$ ). Therefore, to get a clinically relevant difference, a positive mean difference between the midazolam and placebo group of at least 8.5 would be necessary. The two-sided alpha level was fixed at 0.05 , with a beta of 0.10 . Based on these data, a minimum number of 86 in each group was required. We expected a dropout rate of $10 \%$ and thus increased the total number of patients required for inclusion to 192 (96 in each group) accordingly.

Secondary outcome variables were expected to correlate, and with the number of independent measurement scales (dimensions) being eight, we applied a Bonferroni correction to adjust for multiplicity. Therefore, for statistical significance of the secondary outcome, variables were assessed at a two-sided alpha of 0.05/8 $(P<0.006)$.

Data were analyzed according to an intention-to-treat principle. According to previous work, ${ }^{15}$ we applied a robust regression analysis (MM estimation) for our primary and secondary outcome data to allow for non-normal distribution of the outcome variables and for heteroskedasticity. ${ }^{24,25}$ To correct for potential bias, we adjusted our analysis for the baseline imbalance of the corresponding outcome variable and sex. Demographical categorical data were tested with the Pearson Chi square test. Demographical continuous data were analyzed with the Student's t-test for independent observations.

We used SAS version 9.2 (SAS Institute Inc, Cary, NC, USA) for the regression analyses and SPSS software version 21.0 (SPSS Institute, Chicago, IL, USA) for all other analyses.

\section{Results}

Study population

A total of 796 patients were assessed for eligibility, of which 192 were randomized to either the midazolam ( $n=$ 97) or $\mathrm{NaCl} 0.9 \%(n=95)$ group (Fig. 2). There were 285 patients who met one or more of the exclusion criteria, 218 patients refused to participate, and 101 patients were excluded for logistic reasons (e.g., contact isolation or too short an interval between eligibility assessment and start of the surgical procedure).

In retrospect, the baseline measurements were not registered correctly for one patient in the midazolam group where POD 0 data were lacking. In the placebo group, one patient refused further participation after POD 0 assessment because of the outcome of the surgery (nonresectable tumour). Thus, for the final analysis, the midazolam group included 96 participants with available POD 0 data, and in the placebo group, data were available for 95 participants (Fig. 2).

During the postoperative study period, there was little lost to follow-up at POD 3 and/or at POD 7, including both cases mentioned above. The difference in the lost to follow-up between the study groups for any of the measurements was not statistically significant. In the midazolam group, we lost eight participants during follow-up leaving 88 participants at POD 7 (i.e., $96-8$ $=88$ ). In the placebo group, we lost seven participants during follow-up leaving 88 participants at POD 7 (i.e., 95 $-7=88)$.

\section{General characteristics}

Table 1 provides the baseline patient characteristics. Overall, there were no differences in general patient characteristics between the two study arms (Table 1). We found no differences in adverse events (e.g., hypoxia, delirium, unplanned intensive care unit-admission, death) between the groups. All endpoints were skewed nonnormally distributed and all questionnaires had outliers in the data.

\section{Primary outcome}

Postoperative mean (standard deviation) QoR-40 scores were not significantly better in the midazolam group at POD 3 compared with controls [166.4 (17.0) vs 163.9 (19.8), respectively; mean difference, 2.3 ; $95 \%$ confidence interval $[\mathrm{CI}],-2.9$ to $8.4 ; P=0.35]$. Table 2 shows the mean QoR-40 scores for both groups at POD 0 and POD 3. In both groups, the mean scores were high at all time points. After surgery, mean values declined in both groups. 
Table 1 Patient characteristics at baseline

\begin{tabular}{|c|c|c|}
\hline & \multicolumn{2}{|l|}{ Intervention } \\
\hline & $\begin{array}{l}\text { Midazolam } \\
(n=96)\end{array}$ & $\begin{array}{l}\mathrm{NaCl} 0.9 \% \\
(n=95)\end{array}$ \\
\hline \multicolumn{3}{|l|}{ Demographic } \\
\hline \multicolumn{3}{|l|}{ Sex, $n(\%)$} \\
\hline Male & $58(59.8)$ & $62(65.3)$ \\
\hline Age, mean (SD) & $56.5(15.0)$ & $57.5(12.9)$ \\
\hline \multicolumn{3}{|l|}{ Educational level $^{\mathrm{a}}, n(\%)$} \\
\hline Low & $25(26.0)$ & $33(34.7)$ \\
\hline Mid-level & $63(65.6)$ & $49(51.6)$ \\
\hline High & $8(8.3)$ & $13(13.7)$ \\
\hline \multicolumn{3}{|l|}{ Marital status ${ }^{\mathrm{b}}, n(\%)$} \\
\hline Single & $30(31.3)$ & $18(18.9)$ \\
\hline Together & $66(68.8)$ & $77(81.1)$ \\
\hline \multicolumn{3}{|c|}{ Religion (are you religious?), $n(\%)$} \\
\hline Yes & $45(46.9)$ & $49(51.6)$ \\
\hline \multicolumn{3}{|l|}{ Employment, $n(\%)$} \\
\hline Yes & $38(39.6)$ & $50(52.6)$ \\
\hline \multicolumn{3}{|l|}{ Clinical } \\
\hline Weight $^{\mathrm{c}}$, mean $(\mathrm{SD})$ & $79.7(16.3)$ & $79.8(16.1)$ \\
\hline Height $^{\mathrm{d}}$, mean $(\mathrm{SD})$ & $174.4(9.6)$ & $175.0(10.1)$ \\
\hline Heart rate $^{\mathrm{e}}$, mean $(\mathrm{SD})$ & $79.6(17.0)$ & $75.9(14.1)$ \\
\hline \multicolumn{3}{|c|}{ Had surgery before, $n(\%)$} \\
\hline Yes & $89(91.8)$ & $84(88.4)$ \\
\hline \multicolumn{3}{|l|}{$\mathrm{ASA}^{\mathrm{f}}, n(\%)$} \\
\hline ASA I & $8(8.2)$ & $8(8.4)$ \\
\hline ASA II & $43(44.3)$ & $46(48.4)$ \\
\hline ASA III & $43(44.3)$ & $41(43.2)$ \\
\hline ASA IV & $3(3.1)$ & $0(0)$ \\
\hline \multicolumn{3}{|l|}{ Type of surgery, $n(\%)$} \\
\hline General surgery & $88(90.7)$ & $89(93.7)$ \\
\hline Gynaecology & $10(6.2)$ & $4(4.2)$ \\
\hline Urology & $5(3.1)$ & $2(2.1)$ \\
\hline \multicolumn{3}{|c|}{ Oncological surgery, $n(\%)$} \\
\hline Yes & $44(45.4)$ & $53(55.8)$ \\
\hline
\end{tabular}

$\mathrm{NaCl}=$ sodium chloride $\mathrm{SD}=$ standard deviation. Values represent $n$ $(\%)$ or mean (SD) as indicated.

a Low: no education; elementary school; preparatory middle-level vocational education. Mid-level: middle-level vocational education; higher general continued education; higher vocational education. High: preparatory university education; university education.

${ }^{\mathrm{b}}$ Single: unmarried; divorced; widowed. Together: married; living together. ${ }^{\mathrm{c}}$ Weight: body weight in kg. ${ }^{\mathrm{d}}$ Height: body length in $\mathrm{cm}$.

${ }^{\mathrm{e}}$ Heart rate: beats per minute. ${ }^{\mathrm{f}}$ Risk classification according to the American Society of Anesthesiology (ASA).

\section{Secondary outcomes}

Neither the STAI-State and STAI-Trait showed any significant differences between groups on POD 1 (Table 3). At POD 7, there were no between-group differences in the mean QoR-40 score (mean difference, 6.7; Bonferroni-adjusted $95 \% \mathrm{CI},-0.1$ to 15.5 ; unadjusted $P$ value $=0.007$, which did not meet our pre-specified significance level of $P<0.006$ ) (Table 4).

After one week, there were no significant between-group differences in the postoperative HADS-Anxiety scores (Table 4). The MFI (assessing fatigue) was also not different between groups as were the STAS-State, STASTrait, and HADS-Depression scores. Eleven patients in the midazolam group and ten patients in the placebo group filled in the POD 7 questionnaire after hospital discharge.

\section{Discussion}

This study showed that midazolam as premedication did not improve the quality of postoperative recovery in the first week after laparotomy. Although we observed a difference in mean QoR-40 score of 6.7 at POD 7, at the time the present study was designed, a minimal clinically important difference (MCID) for the QoR-40 score was not defined. In our sample size calculation, we had assumed a clinically relevant difference when the mean difference was $\geq 8.5$. We based this value on previous studies that used the QoR-40. ${ }^{15,18}$ After completing our study, Myles et al. published a new MCID for the QoR-40 stating that a change of 6.3 points should be considered a clinically important improvement. ${ }^{26}$ We observed a Bonferroniadjusted $95 \%$ CI of -0.1 to 15.5 for the mean difference, which includes the new MCID value, and therefore there could have been be a clinically relevant improvement in the quality of recovery in the midazolam group at POD 7. Nevertheless, we hesitate to relate our findings to this new MCID since our study was not designed based on POD 7 or on this new MCID value. Future research should be designed and powered for a longer follow-up using this new MCID value of 6.3.

When designing this trial after our previous study in day-surgery patients, ${ }^{15}$ we hypothesized that hospitalized patients who undergo a laparotomy would have higher baseline scores for anxiety, depression, fatigue, and aggression and would have lower baseline quality of recovery scores. Nevertheless, baseline scores were comparable to day-surgery patients. In addition, there was no clinically relevant beneficial effect of premedication on postoperative depression, aggression, and fatigue. We did see a bigger decline in QoR-40 scores after laparotomy compared with day-surgery. ${ }^{15}$ This result was expected since surgery by laparotomy is considered more debilitating than day-surgery. After the first postoperative day, quality of recovery increased for all patients. This may be because laparotomy patients $(52 \%[n$ $=99$ ] of whom had cancer) see their surgery not as 
Table 2 Changes in primary outcome (QoR-40 score) $)^{\mathrm{a}}$ three days after surgery

\begin{tabular}{llllllll}
\hline & $\begin{array}{l}\text { Midazolam } \\
\text { Mean (SD) [n] }\end{array}$ & $\begin{array}{l}\text { NaCL 0.9\% } \\
\text { Mean (SD) [n] }\end{array}$ & Mean (diff) & & \multicolumn{2}{c}{$95 \%$ CI } & \multicolumn{2}{c}{$P^{2}$} \\
\cline { 3 - 7 } & & & Lower & Upper \\
\hline Baseline assessment POD 0 & $179.9(15.9)[96]$ & $179.7(17.6)[95]$ & NA & NA & NA & NA \\
Third day after surgery POD 3 & $166.4(17.0)[91]$ & $163.9(19.8)[91]$ & 2.3 & -2.9 & 8.4 & 0.9 & 0.35 \\
\hline
\end{tabular}

$\mathrm{CI}=$ confidence interval $; \mathrm{NaCl}=$ sodium chloride $; \mathrm{POD}=$ postoperative day.

${ }^{\mathrm{a}}$ Quality of Recovery-40 min-max score: $40-200 .{ }^{\mathrm{b}}$ Mean difference, condition coded as 0 (placebo) and 1 (midazolam). $* P$ values are rounded upwards. Tested by robust regression analysis (adjusted for baseline and sex).

disabling but as a potential cure. One week after surgery, the quality of recovery was even higher showing that the patients were recovering from surgery (ERAS protocol) and were almost ready for discharge.

Grant et al. ${ }^{12}$ Ahn et al. ${ }^{13}$ and Mijderwijk et al. ${ }^{27}$ described reduced PONV after perioperative administration of midazolam. These effects may improve the quality of recovery. Maurice-Szamburski et al. found no improvement in self-reported experience after premedication with oral lorazepam before elective surgery. ${ }^{16}$ Also, Mijderwijk et al. showed that premedication with lorazepam in day-surgery settings had no beneficial effect on quality of recovery. ${ }^{15}$ Patients treated with lorazepam showed even more postoperative anxiety and aggression. Next to a rebound effect, ${ }^{28}$ their results could be explained by the fact that day-surgery induces less anxiety than major procedures. We chose to study a population with a longer postoperative recovery in the hospital. By only including people who had a postoperative stay of at least three days, all perioperative medication lost its pharmacological effect during the hospital stay, and all patients had to deal with their psychological symptoms under the same conditions. ${ }^{29} \mathrm{We}$ did not find any symptoms of paradoxical effects or a rebound phenomenon due to midazolam.

The indication of premedication for the preoperative setting may be less important for non-day-surgery. ${ }^{30}$ Studies showing a positive effect are dated from 1980 to 2000. Healthcare has significantly changed over time. Recently, it was shown that sedative premedication before surgery was no more effective than a placebo, owing to the moderate level of anxiety experienced by patients. ${ }^{31}$ A low preoperative anxiety level in patients might explain the small difference in quality of postoperative recovery in this study. ${ }^{31}$

Our findings should be interpreted in the context of our study methodology and its limitations. We performed our clinical trial in a single-centre setting and focused only on postoperative outcomes. Preoperative outcomes were not included in this study.
Quality of postoperative recovery was measured using the QoR-40 questionnaire. ${ }^{32}$ The QoR-40 (Dutch version) is a translated, well-validated questionnaire but it remains difficult to extrapolate our result to other populations. Expressing negative emotions can be culturally determined, which makes it difficult to compare these aspects between different ethnic groups. ${ }^{33}$ Taking into account differences in anxiety and emotions before and after surgery for males and females, we have adjusted our outcomes for sex. ${ }^{34}$ One limitation of studies using questionnaires such as the QoR-40 is the possibility of a floor/ceiling-effect. ${ }^{35}$ While we had no patients scoring the highest and lowest QoR-40 scores, we nonetheless tried to limit the impact of this phenomenon by correcting for the baseline measurement. We did not measure QoR-40 scores at POD 1. In our opinion, POD 3 was more appropriately timed for major surgery patients. Furthermore, we think that the quality of recovery on POD 3 is a good predictor of the total length of stay after major surgery, which might also be of economical and logistical interest. Although there is no evidence of a training effect for the questionnaires used in this study, it could theoretically bias the outcome data.

We chose midazolam for its proven anxiolytic properties, relatively short duration of action, positive effects on anesthesia, and being the most prescribed premedication drug. ${ }^{411}$ Because we used midazolam in a monitored situation, we could account for possible unpredictable effects or paradoxical reactions. ${ }^{36}$

Ideally the administration of midazolam, or any premedication, should be weight dependent. The standard dose for premedication with oral midazolam in the Erasmus Medical Centre is $7.5 \mathrm{mg}$. With a bioavailability of $40 \%$ of the oral dose we therefore administered $3 \mathrm{mg}$ midazolam intravenously in our study group. ${ }^{37}$ Higher doses might have adverse effects, which would negatively affect the preoperative period. Normally premedication is given orally. With intravenous administration, we wanted to avoid variations in drug resorption kinetics and effectiveness. ${ }^{38}$ Overall, the timing of premedication and 
Table 3 Changes in secondary outcome variables one day after surgery

\begin{tabular}{|c|c|c|c|c|c|c|c|c|c|}
\hline & \multicolumn{2}{|l|}{ Midazolam } & \multicolumn{2}{|l|}{$\mathrm{NaCl} 0.9 \%$} & \multirow[t]{2}{*}{ Mean (diff) $)^{a}$} & \multicolumn{2}{|c|}{$95 \% \mathrm{CI}^{\mathrm{b}}$} & \multirow[t]{2}{*}{$X^{2}$} & \multirow[t]{2}{*}{$P^{\mathrm{b} *}$} \\
\hline & $\begin{array}{l}\text { POD 0 } \\
\text { Mean (SD) } \\
n=96\end{array}$ & $\begin{array}{l}\text { POD } 1 \\
\text { Mean(SD) } \\
n=94\end{array}$ & $\begin{array}{l}\text { POD } 0 \\
\text { Mean(SD) } \\
n=95\end{array}$ & $\begin{array}{l}\text { POD } 1 \\
\text { Mean(SD) } \\
n=93\end{array}$ & & Lower & Upper & & \\
\hline \multicolumn{10}{|l|}{ Anxiety } \\
\hline STAI-State & $38.0(9.1)$ & $32.1(9.0)$ & $40.7(9.7)$ & 34.7 (8.9) & 0.1 & -3.6 & 1.4 & 0.78 & 0.38 \\
\hline STAI-Trait & $31.1(7.1)$ & $29.8(8.8)$ & $32.0(7.1)$ & $28.6(6.8)$ & 2.2 & -0.7 & 2.8 & 1.4 & 0.24 \\
\hline
\end{tabular}

Table 4 Changes in secondary outcome variables over one week

\begin{tabular}{|c|c|c|c|c|c|c|c|c|c|c|}
\hline & \multirow[t]{2}{*}{ Score (min-max) } & \multicolumn{2}{|l|}{ Midazolam } & \multicolumn{2}{|l|}{$\mathrm{NaCl} 0.9 \%$} & \multirow[t]{2}{*}{ Mean (diff) ${ }^{a}$} & \multicolumn{2}{|c|}{$95 \% \mathrm{CIs}^{\mathrm{b}}$} & \multirow[t]{2}{*}{$X^{2}$} & \multirow[t]{2}{*}{$P^{\mathrm{b} *}$} \\
\hline & & $\begin{array}{l}\text { POD } 0 \\
\text { Mean }(\mathrm{SD}) \\
n=96\end{array}$ & $\begin{array}{l}\text { POD } 7 \\
\text { Mean (SD) } \\
n=88\end{array}$ & $\begin{array}{l}\text { POD } 0 \\
\text { Mean (SD) } \\
n=95\end{array}$ & $\begin{array}{l}\text { POD } 7 \\
\text { Mean (SD) } \\
n=88\end{array}$ & & Lower & Upper & & \\
\hline QoR-40 & $40-200$ & $179.9(15.9)$ & $172.9(15.5)$ & $179.7(17.6)$ & 166 (18.4) & 6.7 & 2.1 & 13.3 & 7.32 & $0.007^{\#}$ \\
\hline \multicolumn{11}{|l|}{ Anxiety } \\
\hline STAI-State & $20-80$ & $38.0(9.1)$ & $31.6(8.8)$ & $40.7(9.7)$ & $34.8(10.6)$ & -0.5 & -4.9 & 1.2 & 1.43 & 0.23 \\
\hline STAI-Trait & $20-80$ & $31.2(7.1)$ & $29.1(7.6)$ & $32.0(7.1)$ & $30.0(7.9)$ & 0.1 & -1.4 & 2.0 & 0.13 & 0.72 \\
\hline HADS & $0-21$ & $4.0(3.3)$ & $2.4(2.7)$ & $4.8(3.4)$ & $3.6(3.6)$ & -0.3 & -1.4 & -0.1 & 4.0 & 0.05 \\
\hline \multicolumn{11}{|l|}{ Fatigue } \\
\hline MFI & $20-100$ & $53.8(18.2)$ & $56.6(16.5)$ & $49.9(17.5)$ & $60.1(16.6)$ & -7.4 & -10.3 & 0.1 & 3.71 & 0.05 \\
\hline \multicolumn{11}{|l|}{ Aggression } \\
\hline STAS-State & $10-40$ & $10.5(2.2)$ & $10.8(3.1)$ & $10.3(0.9)$ & $10.7(1.8)$ & -0.1 & -0.1 & 0.1 & 0.59 & 0.44 \\
\hline STAS-Trait & $10-40$ & $13.6(4.3)$ & $13.2(4.1)$ & $13.0(2.8)$ & $13.4(3.1)$ & -0.8 & -1.3 & 0.1 & 2.72 & 0.10 \\
\hline \multicolumn{11}{|l|}{ Depression } \\
\hline HADS & $0-21$ & $3.4(2.7)$ & $3.5(3.3)$ & $3.6(3.3)$ & $4.6(4.3)$ & -0.8 & -1.4 & 0.4 & 1.22 & 0.27 \\
\hline
\end{tabular}

$\mathrm{CI}=$ confidence interval; HADS = Hospital Anxiety and Depression Scale; MFI = Multidimensional Fatigue Inventory; $\mathrm{NaCl}=$ sodium chloride; $\mathrm{POD}=$ postoperative day; QOR-40 = quality of recovery $40 ; \mathrm{SD}=$ standard deviation; STAI = State-Trait Anxiety Inventory; STAS = State-Trait Anger Scale.

${ }^{\mathrm{a}}$ Mean difference condition coded as 0 (placebo) and 1 (midazolam). ${ }^{\mathrm{b}}$ Confidence intervals and $P$ values have not been adjusted for multiple comparisons $* P$ values are rounded upwards. ${ }^{*}$ No significant difference, $P$ for significance after Bonferroni correction $=P<0.006$. Tested by robust regression analysis (adjusted for baseline and sex) using MM estimation.

the start of anesthesia induction in our study reflect common practice. ${ }^{11}$

Anesthesia techniques were not standardized for all patients. Blinding for the treating anesthesiologist was hard to accomplish in some patients because of the sedative effect of midazolam. This may have caused them to administer less hypnotic anesthetics (i.e., propofol) in already sedated patients. Nevertheless, we did not find differences in the anesthetic regimens and believe that differences in outcome are best explained by the use of midazolam. We did not match our participants. By randomizing, it is assumed that all confounders are distributed equally in both groups. Therefore, we did not correct for different type of laparotomies, anesthesia techniques, or other surgical factors. Anxiety might be affected by factors like education level, marital status, and employment status. Therefore, we analyzed our two groups for possible differences after randomization. Despite a somewhat unbalanced distribution, we found no statistically significant differences between the two groups. We could not include 101 patients for logistic reasons. We have no reason to believe this led to selection bias because we included consecutive patients. 
Based on several recent publications, some of the (especially older) patients may have much more benefit from a benzodiazepine-free anesthesia to avoid postoperative delirium and postoperative cognitive dysfunction. ${ }^{39-41}$ Both states are related with higher morbidity and mortality after surgery. ${ }^{42}$ Thus, clear indications are needed for when to administer benzodiazepines as premedication because it might not suit all patients. In this study, no conclusions could be made on the causality of benzodiazepine administration and the incidence of delirium because the incidence of delirium was too low $(n=1)$. Based on the now available evidence, future research should focus on patients with low preoperative QoR-40 or high anxiety levels to investigate whether premedication would improve their postoperative quality of recovery. Outcome parameters to measure should be linked to the ERAS-milestones (e.g., mobilization, oral intake). Furthermore, the sedative (side-) effects of benzodiazepine deserve more attention (e.g., time to extubation, postoperative delirium).

\section{Conclusion}

Our study did not find an improved quality of recovery after premedication with midazolam in adult hospitalized patients undergoing a laparotomy. These findings are in line with those from others, and raise questions as to the general use of midazolam for anesthetic premedication.

Funding Department of Anesthesiology of Erasmus University Medical Centre Rotterdam, The Netherlands.

Financial support and sponsorship This work was supported by the Department of Anesthesiology, Erasmus Medical Centre, Rotterdam, the Netherlands. Presentation: none, preliminary data were not previously presented.

All authors have completed the ICMJE uniform disclosure form and declare: no support from any organisation for the submitted work; no financial relationships with any organisations that might have an interest in the submitted work in the previous three years; and no other relationships or activities that could appear to have influenced the submitted work.

Transparency declaration The lead author affirms that this manuscript is an honest, accurate, and transparent account of the study being reported; that no important aspects of the study have been omitted; and that any discrepancies from the study as planned (and, if relevant, registered) have been explained.

Conflicts of interest None declared.

Editorial responsibility This submission was handled by Dr. Hilary P. Grocott, Editor-in-Chief, Canadian Journal of Anesthesia.

Author contributions Stefan van Beek, Markus Klimek, and Robert $J$. Stolker contributed to all aspects of this manuscript, including study conception and design; acquisition, analysis, and interpretation of data; and drafting the article. Jeroen Kroon and Koen Rijs contributed to the acquisition, analysis, and interpretation of data. Hendrik-Jan Mijderwijk contributed to the analysis and interpretation of data, and to drafting the article.

Open Access This article is distributed under the terms of the Creative Commons Attribution-NonCommercial 4.0 International License (http://creativecommons.org/licenses/by-nc/4.0/), which permits any noncommercial use, distribution, and reproduction in any medium, provided you give appropriate credit to the original author(s) and the source, provide a link to the Creative Commons license, and indicate if changes were made.

\section{References}

1. Norris W, Baird WL. Pre-operative anxiety: a study of the incidence and aetiology. Br J Anaesth 1967; 39: 503-9.

2. Johnson M. Anxiety in surgical patients. Psychol Med 1980; 10: 145-52.

3. Ramsay MA. A survey of pre-operative fear. Anaesthesia 1972; 27: 396-402.

4. Maranets I, Kain ZN. Preoperative anxiety and intraoperative anesthetic requirements. Anesth Analg 1999; 89: 1346-51.

5. Caumo W, Schmidt AP, Schneider CN, et al. Risk factors for postoperative anxiety in adults. Anaesthesia 2001; 56: 720-8.

6. Badner NH, Nielsen WR, Munk S, Kwiatkowska C, Gelb AW. Preoperative anxiety: detection and contributing factors. Can J Anaesth 1990; 37: 444-7.

7. Ray A, Fitzgibbion G. Stress arousal and coping with surgery. Psychol Med 1981; 11: 741-6.

8. Kindler CH, Harms C, Amsler F, Ihde-Scholl T, Scheidegger D. The visual analog scale allows effective measurement of preoperative anxiety and detection of patients' anesthetic concerns. Anesth Analg 2000; 90: 706-12.

9. Gras S, Servin F, Bedairia E, et al. The effect of preoperative heart rate and anxiety on the propofol dose required for loss of consciousness. Anesth Analg 2010; 110: 89-93.

10. Olkkola KT, Ahonen J. Midazolam and other benzodiazepines. Handb Exp Pharmacol 2008; 182: 335-60.

11. Kain ZN, Sevarino F, Pincus $S$, et al. Attenuation of the preoperative stress response with midazolam: effects on postoperative outcomes. Anesthesiology 2000; 93: 141-7.

12. Grant MC, Kim J, Page AJ, Hobson D, Wick E, Wu CL. The effect of intravenous midazolam on postoperative nausea and vomiting: a meta-analysis. Anesth Analg 2016; 122: 656-63.

13. Ahn EJ, Kang H, Choi GJ, Baek CW, Jung YH, Woo YC. The effectiveness of midazolam for preventing postoperative nausea and vomiting: a systematic review and meta-analysis. Anesth Analg 2016; 122: 664-76.

14. Kain ZN, Sevarino FB, Rinder $C$, et al. Preoperative anxiolysis and postoperative recovery in women undergoing abdominal hysterectomy. Anesthesiology 2001; 94: 415-22.

15. Mijderwijk $H$, van Beek $S$, Klimek M, Duivenvoorden HJ, Grüne $F$, Stolker RJ. Lorazepam does not improve the quality of recovery in day-case surgery patients: a randomised placebocontrolled clinical trial. Eur J Anaesthesiol 2013; 30: 743-51.

16. Maurice-Szamburski A, Auquier P, Viarre-Oreal V, et al. Effect of sedative premedication on patient experience after general anesthesia: a randomized clinical trial. JAMA 2015; 313: 916-25.

17. Myles PS, Hunt JO, Nightingale CE, et al. Development and psychometric testing of a quality of recovery score after general anesthesia and surgery in adults. Anesth Analg 1999; 88: 83-90. 
18. Myles PS, Weitkamp B, Jones K, Melick J, Hensen S. Validity and reliability of a postoperative quality of recovery score: the QoR40. Br J Anaesth 2000; 84: 11-5.

19. Defares $P B$, van der Ploeg HM, Spielberger $C D$. Handleiding bij de Zelf beoordelings Vragenlijst ZBV. Een Nederlandstalige bewerking van de Spielberger State-Trait Anxiety Inventory. Lisse: Swets \& Zeitlinger; 1980: 1-35.

20. Smets EM, Garssen B, Bonke B, de Haes JC. The Multidimensional Fatigue Inventory (MFI) psychometric qualities of an instrument to assess fatigue. J Psychosom Res 1995; 39: 315-25.

21. Zigmond AS, Snaith RP. The hospital anxiety and depression scale. Acta Psychiatr Scand 1983; 67: 361-70.

22. Spinhoven PH, Ormel J, Sloekers PP, Kempen GI, Speckens AE, Van Hemert AM. A validation study of the Hospital Anxiety and Depression Scale (HADS) in different groups of Dutch subjects. Psychol Med 1997; 27: 363-70.

23. Van der Ploeg HM, Defares PB, Spielberger CD. Handleiding bij de Zelf Analyse Vragenlijst, een Nederlandstalige bewerking van de Spielberger State-Trait Anger Scale. Lisse: Swets \& Zeitlinger; 1982. p. 1-48.

24. Yohai VJ. High breakdown-point and high efficiency robust estimates for regression. Ann Stat 1987; 15: 642-56.

25. Susanti Y, Pratiwi H, Sri Sulistijowati H, Liana T. M estimation, $\mathrm{S}$ estimation, and $\mathrm{MM}$ estimation in robust regression. Int $\mathbf{J}$ Pure Appl Math 2014; 91: 349-60.

26. Myles PS, Myles DB, Galagher W, Chew C, MacDonald N. Dennis A. Minimal clinically important difference for three quality of recovery scales. Anesthesiology 2016; 125: 39-45.

27. Mijderwijk $H$, van Beek $S$, Duivenvoorden HJ, Stolker RJ. Effectiveness of benzodiazepine premedication on recovery in day-case surgery: a systematic review with meta-analysis. Minerva Anestesiol 2016; 82: 438-64.

28. Chouinard $G$. Issues in the clinical use of benzodiazepines: potency, withdrawal, and rebound. J Clin Psychiatry 2004; 64: 712.

29. Steiner C, Steurer MP, Mueller D, Zueger M, Dullenkopf A. Midazolam plasma concentration after anesthesia premedication in clinical routine - an observational study: : midazolam plasma concentration after anesthesia premedication. BMC Anesthesiol 2016. DOI: https://doi.org/10.1186/s12871-016-0262-6.

30. Bucx MJ, Krijtenburg P, Kox M. Preoperative use of anxiolyticsedative agents; are we on the right track? J Clin Anesth 2016; 33: $135-40$.

31. Beydon L, Rouxel A, Camut N, et al. Sedative premedication before surgery - a multicentre randomized study versus placebo. Anaesth Crit Care Pain Med 2015; 34: 165-71.
32. Myles PS. Measuring quality of recovery in perioperative clinical trials. Curr Opin Anaesthesiol 2018; 31: 396-410.

33. Eisinger F, Geller G, Burke W, Holtzman NA. Cultural basis for differences between US and French clinical recommendations for women at increased risk of breast and ovarian cancer. Lancet 1999; 353: 919-20.

34. Mijderwijk $H$, Klimek $M$, van Beek $S$, van Schaik $R H$, Duivenvoorden HJ, Stolker RJ. Implication of UGT2B15 genotype polymorphism on postoperative anxiety levels in patients receiving lorazepam premedication. Anesth Analg 2016; 123: 1109-15.

35. Baker DW, Hays RD, Brook RH. Understanding changes in health status. Is the floor phenomenon merely the last step of the staircase? Med Care 1997; 35: 1-15.

36. Mancuso CE, Tanzi MG, Gabay M. Paradoxical reactions to benzodiazepines: literature review and treatment options. Pharmacotherapy 2004; 24: 1177-85.

37. Greenblatt DJ, Abernethy DR, Locniskar A, Harmatz JS, Limjuco $R A$, Shader RI. Effect of age, gender, and obesity on midazolam kinetics. Anesthesiology 1984; 61: 27-35.

38. van Rongen A, Kervezee $L$, Brill $M$, et al. Population pharmacokinetic model characterizing 24-hour variation in the pharmacokinetics of oral and intravenous midazolam in healthy volunteers. CPT Pharmacometrics Syst Pharmacol 2015; 4: 45464.

39. Kassie GM, Nguyen TA, Kalisch Ellett LM, Pratt NL, Roughead $E E$. Preoperative medication use and postoperative delirium: a systematic review. BMC Geriatr 2017. DOI: https://doi.org/10. 1186/s12877-017-0695-x.

40. Burry LD, Williamson DR, Mehta S, et al. Delirium and exposure to psychoactive medications in critically ill adults: a multi-centre observational study. J Crit Care 2017; 42: 268-74.

41. National Institute for Health and Care Excellence. Delirium: prevention, diagnosis and management. Publication July 2010. Evidence update 12 November 2014. Available from URL: www. nice.org.uk/guidance/cg103/evidence (accessed July 2019).

42. Berger $M$, Nadler JW, Browndyke $J$, et al. Postoperative cognitive dysfunction: minding the gaps in our knowledge of a common postoperative complication in the elderly. Anesthesiol Clin 2015; 33: 517-50.

Publisher's Note Springer Nature remains neutral with regard to jurisdictional claims in published maps and institutional affiliations. 